\title{
A Review on the Importance of Teacher's Efforts to Prepare High School Graduates' Soft Skills in Vocational High School
}

\author{
Rudi Nur Syamsudin ${ }^{1}$ and Sukardi ${ }^{2}$ \\ ${ }^{I}$ Technological and Vocational Education, Graduate School of Yogyakarta State \\ University, Indonesia \\ ${ }^{2}$ Yogyakarta State University, Indonesia \\ Isyamsudin_rudi@yahoo.com, ${ }^{2}$ sukardi1953@gmail.com
}

\begin{abstract}
The importance of soft skills mastering is reflected in the worker criterion needed in the work fields. Unfortunately, vocational high school as the educational institution which prepares the graduates to be ready to work does not optimally prepare the graduates' soft skills. This paper presents a review on the importance of vocational high school teacher's efforts in portraying the graduates' soft skills based on the work field needs. First, the viewpoint related to the organization of the vocational high school is discussed by analyzing its strength and weakness. Second, the review of literature related to the importance of soft skills mastering is presented. Finally, it can be concluded that the teacher's efforts in preparing the graduates' soft skills are pivotal. Therefore, a teacher is the director of the teaching and learning process.
\end{abstract}

Keywords: Teacher's efforts, Vocational high school, Soft skills, Review

\section{Introduction}

Vocational high school is one of formal education institutions in Indonesia [1]. Based on Government Regulation of Indonesia number 17 Year 2010 about Educational Management and Organization, vocational high school is a formal educational institution which organizes vocational education in high schools as the next level of junior high school0s. The vocational high school aims to prepare the graduates to work. Therefore, vocational high school as an educational institution which has the important role in preparing the workers is demanded to follow the market need which is steadily changing.

As stated in Strategic Plan of Vocational High School Training Directorate (2015-2019), the government, especially the vocational high school training directorate, is responsible for developing the quality human recourses. It is based on the policy of the Ministry of Culture and Education which set the ratio of vocational high schools and senior high schools as 70:30. The aim of that policy is to afford the qualified vocational high school graduates who are ready to work. In other hand, the policy aims to decrease the amount of unemployment and to increase the national economy.

In this globalization era, the science and technology have developed rapidly. This globalization era demands the quality of human resources in every aspects of life which can compete in this era. In 2015, Indonesia has to face the agreement of ASEAN Economic Community related to the liberalisation of goods, services, and skilled workers. It will cause an easy access for skilled workers from ASEAN countries to enter Indonesia so that if the domestic workers are not ready, the amount of unemployment in Indonesia will increase. The 
government has to make some policies to upgrade the quality of the workers. One of the policies is by improving the quality graduates of vocational high school.

There are a lot of changes in every aspect of life in 21 st century. The vocational high school graduates should not only be prepared with the hard skills but also the soft skills. It is ironic that vocational high school as educational institutions which prepared the skilled graduates focuses more on the aspect of skill and knowledge or the hard skills. However, the learning ratio for the soft skills is still less. In fact, the work field prioritizes the soft skills than the hard skills. Sandroto [2] state that the success at work is $75 \%$ determined by soft skills and $25 \%$ influenced by hard skills. In addition, soft skills are the characters which become the key to success and function to improve the effectiveness of working.

The hard skills competency is the minor requirement for the graduates when they enter certain work field based on their majority. In contrast, the soft skill is the graduates' skill to determine the self-development at the workplace. Hendarman [3] stated that the graduates have to have these soft skills: (1) communication skills; (2) critical and creative thinking; (3) inquiry/reasoning skills; (4) interpersonal skills; (5) multicultural/multilingual literacy; (6) problem solving.

To prepare graduates who are ready to work, there are a lot of ways to be done. It can be done by designing curriculum based on the purpose of the vocational high school, improving the teachers' professionalism, maintaining the cooperation with industrial workplace, and improving double system education. It can also be achieved by improving the quality of internship, holding teaching factory program, training from the stake holder of employment, facilitating the learning processes with good tool and equipment, managing good school finance, creating good learning environment at school, improving the quality of teaching and learning in the class, and many others.

The learning processes are the first step to improve the quality of skilled graduates who are ready to work. As stated in the Law number 20 Year 2003 about National Education System, learning is an interaction process between the students and the teacher, and between the students and the learning resources in a learning environment. It means that during the learning process there should be follow up interaction between the students and the teacher. The teacher has many roles as the director and also as the actor during the teaching and learning process and he is the prominent factor in the success of teaching and learning process at school. Even though the curriculum is good, the tool and equipment are complete but if there is not a quality and competent teacher, it is impossible to create an optimal teaching and learning process. Moreover, the aim to prepare skilled graduates cannot be achieved.

A quality teacher is a teacher who has deep knowledge and teacher's professional competence. The competencies include the pedagogic competence, personality competence, professional competence, and social competence. The teachers' responsibility is not only about delivering the materials. Moreover, a teacher should also have the knowledge and awareness of graduates' requirements needed by the workplace. That knowledge and awareness will be useful for the students to prepare their perception about the graduates' criteria which is needed by the workplace and the skills that have to be had by them.

Developing students' soft skills is not an easy work. The most effective way is by setting chances for the students to practice the activities which can build their soft skills. The activities should be done regularly based on the standardized procedure. As an example, when the students do their practicum, the output of it is a work product. The practicum becomes a learning activity which can train students' soft skills. The activity can develop the students' critical thinking, responsibility, problem solving, expressing opinion, and other soft skills ability. The practicum activity makes the students practice working; have job responsibility; 
and have to be brave to express their opinion when they face some problems during the practicum. In this practicum learning, the teacher plays role as the facilitator who answer the students' questions and give solution when the students express their opinion related to the problems. The teacher also has to guide the students doing and finishing their job during the practicum. Indeed, the teacher has to always be in the class during the practicum learning process even though the learning process is student-centred.

ASEAN Economic Community (AEC) as the globalism era in 21 st century causes some impacts in every aspect of life. One of them is the freedom for worker threat in South East Asia. The worker quality needed is not only the hard skills but also the soft skills. The vocational high schools which still focus on preparing the students' hard skills have to be more aware of this situation. They have to set the strategy how to prepare not only the students' hard skills but also their soft skills. The soft skills include the critical thinking skill, written and verbal communication skill, teamwork creativity skill, examining skill, and problem solving skill as the skills to face the future.

The teacher as the actor in the teaching and learning processes has roles and responsibility to prepare students' soft skills without ignoring other factors in the learning processes. The teachers' efforts in preparing the students' soft skills are crucial so that the vocational high schools as an educational institution which prepare the graduates to be ready to work have to support this idea.

Motivated from above explanation, this paper presents a review on the importance of teacher's efforts to prepare high-school graduates' soft skills in vocational high school. This work will show that the teacher's efforts in preparing the graduates' soft skills are pivotal.

\section{Proposed method}

This paper uses the secondary data from journal articles, books, conference proceedings papers, and online journals. Then those data are synthesized and resulted as this data study. The existing related literatures have mostly focused on teacher's efforts to prepare highschool graduates. They comprise topics as following: (1) Education operation in vocational high school; (2) The relation between vocational high school and work; (3) The roles of vocational high school teachers; (4) The graduates' soft skills. In summary the following [Figure 1] depicts our review method.

\section{A review on the importance of teacher's efforts to prepare high-school graduates' soft skills in vocational high school}

\subsection{Education operation in vocational high school}

Vocational high school is one of educational institutions in Indonesia. Basically high vocational education is high school education which focuses on developing the students' ability to do certain job (Government Regulation Number 29 Year 1990). Based on its type, the vocational high school organizes the educational programs which are adapted with the work fields (Government Regulation Number 29 Year 1990). It means that the program studies in vocational high schools are based on the needs in workplace and the market and community condition. 


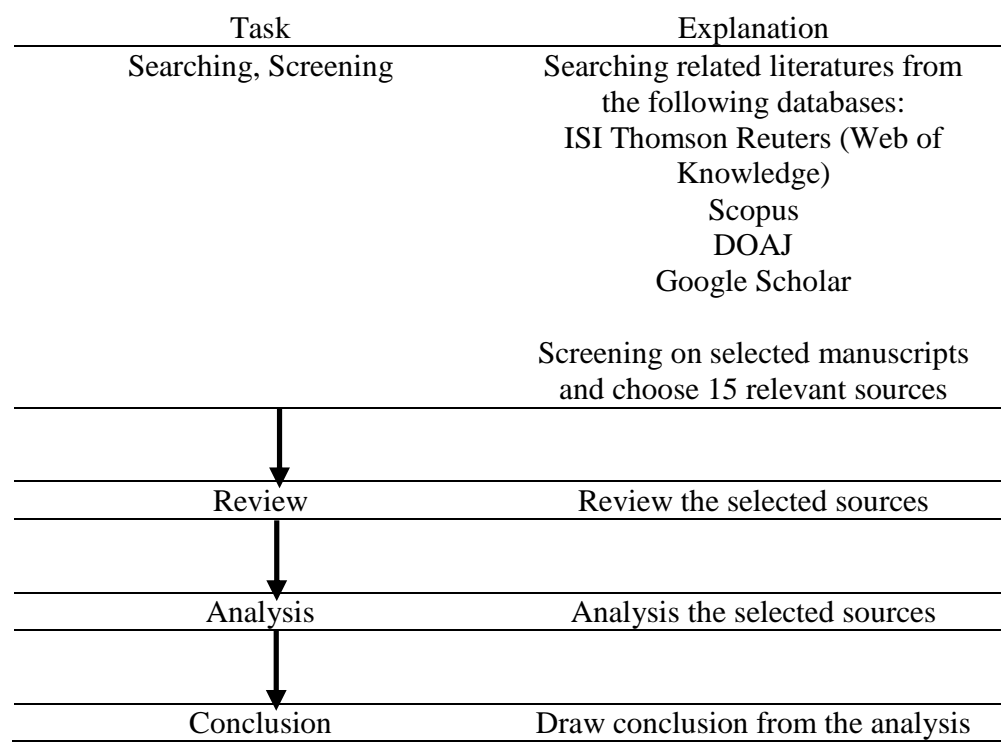

Figure 1. Review approach

The students can choose the program study based on their talent and preference. It is based on the idea that the vocational high school is the educational institution and also the part of national education system which more focuses on developing the graduates' ability to work in certain field. That is the aim of the vocational high school. As stated in Law Number 20 Year 2003, there are two aims of vocational high school: the general aims and the specific aims. The general aims of vocational high school include: (a) improving the students' belief in the Almighty One; (b) developing the students' competence to be a good citizenship who are well behave, healthy, knowledgeable, skilled, creative, autonomous, free, and responsible; (c) developing the students' competence to have good national knowledge and to understand the multiculturalism of Indonesia; and (d) developing the students' competence to be aware of their environments, to look after the nature, and to have the ability to use the natural resources wisely.

Indeed, the specific aims of vocational high school education involve: (a) preparing the students' to be productive human, able to work independently, able to fill in the job opportunity based on their study program; (b) preparing the students to choose their career, to have work ethic and skilled competence, to be able to adapt in the workplace, and to develop the work professionalism based on their study program; (c) supporting the students with knowledge, technology awareness, and culture awareness so that they can actualize their self independently or through the higher education; and (d) actualizing the students' skills based on their study program.

Unfortunately there are some weak points in the operation of vocational high school such as only focusing on preparing the students to be a worker than an entrepreneur, responding the demand of economic development slowly, mismatching with the demand in workplace, and not giving a guarantee that the students can afford standardized work based on their study program [4]. Besides, the learning process in vocational high school is dominated by the activities focusing on developing the hard skills. The portion for actualizing the soft skills in the learning process is still low. The lack of soft skills training causes less number of 
graduates accepted in the work fields. Nowadays, the requirement to be accepted in the work fields considers the soft skills quality of graduates [5].

In conclusion, vocational high school is an educational institution whose duties is to develop the students' knowledge and skill based on the students' competence and study program and to prepare the students' adaptation and competitiveness competence to face the work fields. Vocational education not only develops the students' hard skills but also the students' soft skills.

\subsection{The relation between vocational high school and work}

Vocational high school has closed relation with the work fields. As discussed before, the vocational high school executes a lot of study programs which are suited by the needs in the work fields. Besides, the aim of vocational high school is to prepare the skilled worker in certain work fields. In other word, the vocational high school becomes a vocational high school institution which functions as the producer of skilled graduates based on the needs in the work fields and certain majority.

However it is important to be known that all education levels are set and aimed to fill the needs in the work fields. Because the profile in work fields and industrial fields is varied and divided into stratum, the planned education must follow that profile. The graph below shows the relation between the education structure/level and the worker structure as stated by the Ministry of Culture and Education.

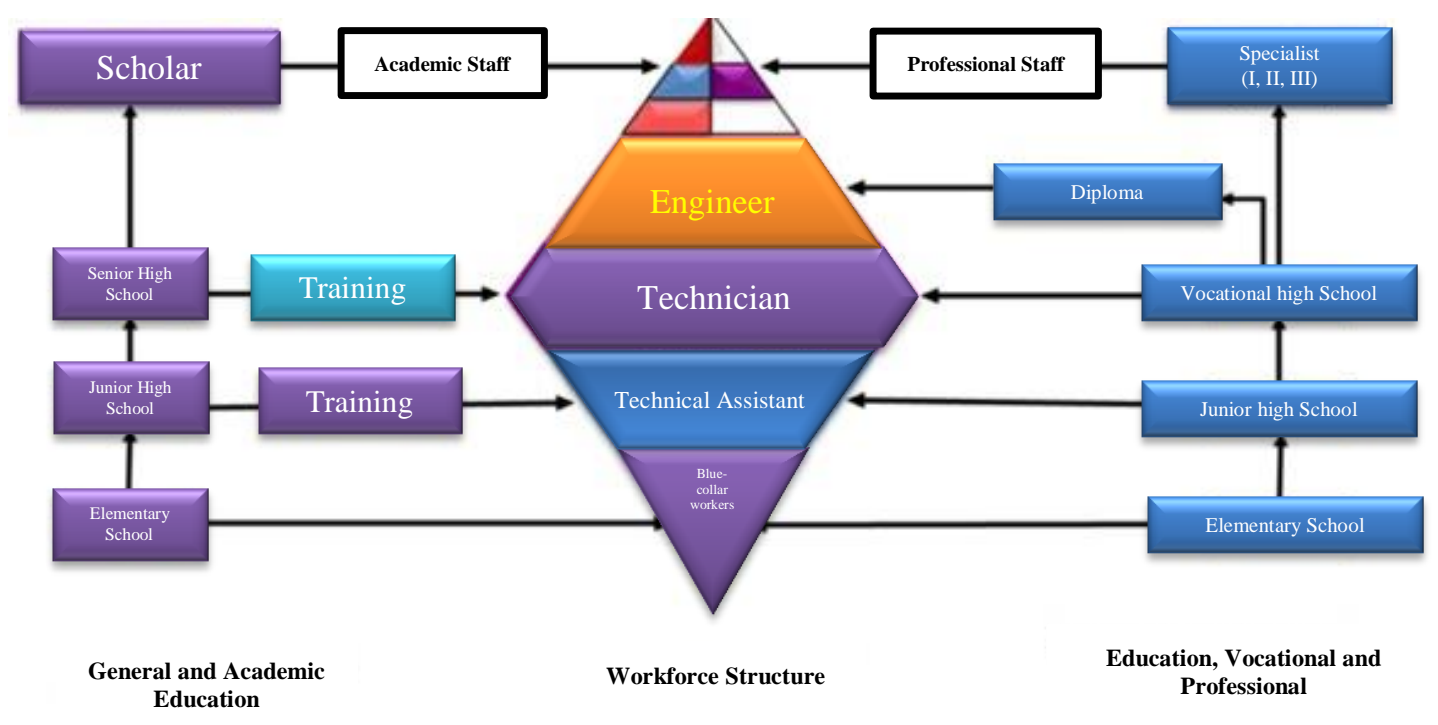

Figure 2. The relation between education structure and worker

Based on the [Figure 2] above, it can be seen that the worker structure changes from pyramid in the shape of triangle become rhombus along with the education structure. Workers of senior high school or vocational high school become technical worker who has to be ready for use in the work field. As stated before, as the science and technology develop, there are changes in the work profile in which before the sophisticated technology exits, the work is mostly done by man physical power but now in doing the work, the thinking skills and soft skills are more needed. 
Nowadays, a lot of companies minimize the use of man power and tend to use machine during the production process. Moreover, the skill competences standardized by the employer to the worker candidate include the competence based on the majority (hard skills), and mental competence such as attitude, cooperation, and motivation which are part of soft skills. Ironically, most of schools in Indonesia have not shaped up their graduates to have those skills. As a result, the high school graduates get difficulty to compete in the work fields [6].

\subsection{The roles of vocational high school teachers}

In general, role is defined as someone's status in the society which can indicate someone's work ability. Retnowati [7] state that the role is an organized sector of an actor's orientation which constitutes and defines his participation in an interactive process. It involves a set of complementary expectation concerning his own actions and those of others with whom he interacts. Both the actor and those with whom he interacts process these expectations. In short, the role defines as an organized section on someone's behaviour which guides and determines his participation in the interaction process. Through his role, someone involves the immediate hope, keeps up the action, and has interaction with the others. The roles are usually influenced by whom someone is interacted with.

In order to be a vocational high school teacher who can do the teacher's tasks professionally during the teaching and learning process, the teacher should play some roles in the teaching and learning process, for example as a facilitator, as a motivator, as an inspiration, as an innovator [1]. Irawan [8] also states that nowadays the teacher's role is not only transferring the knowledge to the students. The teacher also has to develop the students' critical thinking skill. Indeed, to build the students' critical thinking skill, it is the teacher's role as the facilitator and the students' as the subject of the learning not the object of it.

Therefore, the vocational high school teachers are demanded to be able to deliver the learning materials which can facilitate the development of students' skills in certain majority based on the current needs in the work fields. They should not only develop the students' hard skills but also should nurture the mastery of soft skills in students' mind. One of the efforts that can be done by the teachers to help the students' master the soft skills is through the integration of soft skills aspect in the syllabus and lesson plan.

The efforts can also be done by changing the learning style into student-centred learning. It means that the learning is centred on the students so that the students are active during the teaching and learning process. The other effort which can be implemented by the teacher to prepare the students' soft skills is by using varied learning style models. The teacher can use these kinds of learning models: project based learning, problem-solving based learning, hands-on learning, activities based learning, and work based learning. By implementing those learning models, it is expected that the students are more active during the learning process and they can master the soft skills [9].

In conclusion, a teacher should not only have a single role during the teaching and learning process which is to deliver the learning materials. The teacher also plays roles as the facilitator, motivator, inspiration, and innovator for the students. Moreover, as a vocational

high school teacher, his or her role is not only about transferring the hard skills. The vocational high school teacher also has a responsibility to train and develop the students' soft skills. 


\subsection{The Graduates' soft skills}

The worker criterion needed in this globalization era is a human resource that is able to balance the hard skills and soft skills. Vocational high school graduates as a worker candidate should not only have the hard skills, but should also master the soft skills as the supporting aspect of the hard skills. Jones in [10] states that soft skills are life skill and proficiency related to oneself, group, society, and the Almighty Creator. The urgency of the soft skills will be implemented usefully when the graduates enter the real life or work fields. The soft skills are categorized into communicative ability, affective ability, language ability, cooperative ability, moral and etiquette, well behaviour, and spiritual ability.

Experts also states that the quality of soft skills mastery can be seen from someone's behaviour including his or her interaction in the society, language proficiency, custom, or other behaviours which support someone's optimism [11]. Hadiyanto [12] divides the soft skills into two categories: intrapersonal skill and interpersonal skill. The intrapersonal skill is someone's ability to control their selves to actualize his or her work ability maximally. The intrapersonal skill includes responsibility, confidence; socialize ability, self-control, integrity or honesty and creativity. Moreover, the interpersonal skill is someone's ability to interact with others for the optimum actualization of work ability. This skill involves participating as a group member, teaching the knowledge and/or idea with others, serving the customer, having negotiating ability, marketing ability, and organizing ability.

In short, from the previous discussion, it can be concluded that the soft skills are everyone's ability which builds someone's character. The mastery of soft skills can be developed maximally and is one of the indicators needed in the work fields. The soft skills are the supplement to the hard skills. Both of them have to balance and support each other. So that, it is important for the high school graduates to master the soft skills and it is a must for the teacher to develop the graduates' soft skills.

Tubaishat [13] adds that the factor that makes someone survive in the work fields is $80 \%$ determined by his or her mind set and $20 \%$ determined by the technical skills. Levina [14] elaborate their research finding that the work fields, both business fields and industrial fields, tend to employ the graduates whose have common sense, positive working ethos, and good communication ability. Moreover, the graduates are able to implement the basic principle to finish the work punctually, in team, and based on the budget. Here are the graduates' skills needed by the business field/industrial field [15].

Table 1. Skill criteria in the business field/industrial field

\begin{tabular}{|c|c|c|}
\hline No & Quality/Skill & Importance \\
\hline 1 & Communication Skills & 4,8 \\
\hline 2 & Honesty/Integrity & 4,7 \\
\hline 3 & Interpersonal Skills & 4,5 \\
\hline 4 & Motivation/Initiative & 4,5 \\
\hline 5 & Strong Work Ethic & 4,5 \\
\hline 6 & Teamwork Skills & 4,5 \\
\hline 7 & Analytical Skills & 4,4 \\
\hline 8 & Flexibility/Adaptability & 4,3 \\
\hline 9 & Computer Skills & 4,1 \\
\hline 10 & Detail Oriented & 4,0 \\
\hline
\end{tabular}


A Review on The Importance of Teacher's Efforts to Prepare High-School Graduates' Soft Skills in Vocational High School

\begin{tabular}{|c|c|c|}
\hline 11 & Leadership Skills & 4,0 \\
\hline 12 & Organizational Skills & 4,0 \\
\hline 13 & Self-Confidence & 4,0 \\
\hline 14 & Friendly/Outgoing Personality & 3,8 \\
\hline 15 & Tactfulness & 3,8 \\
\hline 16 & Well Mannered/Polite & 3,8 \\
\hline 17 & Creativity & 3,6 \\
\hline 18 & GPA (3.0 or better) & 3,6 \\
\hline 19 & Entrepreneurial Skills/Risk-Taker & 3,2 \\
\hline 20 & Sense Of Humour & 3,2 \\
\hline
\end{tabular}

From [Table 1] above, the soft skills are needed by the graduates to achieve the success in the work field. As discussed before, the common problem faced by the work fields especially the industrial field is related to the soft skills aspect. Hence, the soft skills have the pivotal role for someone to start or do the work successfully and to avoid the risks in industrial world threat.

\section{Conclusion}

Vocational high school is an educational institution in high school level which aims to prepare the graduates to be ready to work based on the study program. However, the current efforts to prepare the vocational high school graduates are still dominated by the training of the hard skills, but the efforts to develop the graduates' soft skills are considered low. The teacher as the director of the teaching and learning process has the responsibility and role to prepare the graduates' soft skills. One of the efforts to prepare the graduates' soft skills is by changing the learning strategy from teacher-centred to student-centred. The teacher should implement the learning model which aims to train the mastery of the soft skills such as project based learning, problem solving based learning, hands-on learning, activities-based learning, and work based learning. The teacher should also do other efforts which are necessary to facilitate vocational high school graduates with the soft skills. Because the vocational high school teacher has the pivotal efforts in preparing the graduates' soft skills, there should be supports from every party. It includes the vocational high school as the educational institution and the work fields as the customer of the vocational high school output. The cooperation, facility, and supports from those three parties (the teacher, the vocational high school, and the work field) have to support each other. It aims to create graduates who are ready to work, skilled, able to compete, and needed by the work fields.

\section{Acknowledgement}

The authors would like to thank Yogyakarta State University for supporting this research.

\section{References}

[1] Y. Estriyanto, S. Kersten, P. Pardjono, and H. Sofyan, "The missing productive vocational high school teacher competency standard in the Indonesian education system,” J. Tech. Educ. Train., vol.9, no.1, (2017)

[2] C. W. Sandroto, B. P. D. Riyanti, and M. Tri Warmiyati, "Entrepreneurial intention and competencies of vocational and high school graduates in Indonesia," Pertanika J. Soc. Sci. Humanit., vol.26, pp.225-236, (2018) 
[3] A. F. Hendarman and U. Cantner, "Soft skills, hard skills, and individual innovativeness," Eurasian Bus. Rev., vol.8, no.2, pp.139-169, (2018) DOI: 10.1007/s40821-017-0076-6

[4] S. W. D. Purba and W. Y. Hwang, "Investigation of learning behaviors and achievement of vocational high school students using an ubiquitous physics tablet PC App,” J. Sci. Educ. Technol., vol.26, no.3, pp.322-331, (2017) DOI: 10.1007/s10956-016-9681-x

[5] M. V. Gruzdev, I. V. Kuznetsova, I. Y. Tarkhanova, and E. I. Kazakova, “University graduates' soft skills: The employers' opinion,” Eur. J. Contemp. Educ., vol.7, no.4, pp.690-698, (2018) DOI: 10.13187/ejce d.2018.4.690

[6] A. S. Hoffait and M. Schyns, "Early detection of university students with potential difficulties," Decis. Support Syst., vol.101, pp 1-11, (2017) DOI: 10.1016/j.dss.2017.05.003

[7] E. Retnowati, Suprapto, M. A. Jerusalem, K. Sugiyarto, and Wagiran, "Innovative teaching and learning methods in educational systems: proceedings of the International Conference on Teacher Education and Professional Development (INCOTEPD 2018),” October 28, 2018, Yogyakarta, Indonesia. Routledge, (2018)

[8] V. T. Irawan, E. Sutadji, and Widiyanti, "Blended learning based on schoology: Effort of improvement learning outcome and practicum chance in vocational high school," Cogent Educ., vol.4, no.1, 1282031, (2017) DOI: 10.1080/2331186X.2017.1282031

[9] S. Taş, "The effect of vocational high school administrators' leadership behaviors on teacher job satisfaction," Univers. J. Educ. Res., vol.5, no.11, pp.2092-2100, (2017) DOI: 10.13189/ujer.2017.051126

[10] M. Jones, C. Baldi, C. Phillips, and A. Waikar, "The hard truth about soft skills: What recruiters look for in business graduates.," Coll. Stud. J., vol.50, no.3, pp.422-428, (2016)

[11] A. Ali and S. Mahmod, "Mastering soft skills in the implementation of work-based learning among community college students," Pertanika J. Soc. Sci. Humanit., vol.795, no.1, pp.012004, (2017)

[12] Hadiyanto, A. Mukminin, Failasofah, N. Arif, N. Fajaryani, and A. Habibi, "In search of quality student teachers in a digital era: Reframing the practices of soft skills in teacher education," Turkish Online J. Educ. Technol., vol.16, no.3, pp.71-78, (2017)

[13] A. Tubaishat, "Issues in informing science and information technology can e-portfolio improve students' readiness to find an IT career?,” Issues Informing Sci. Inf. Technol., vol.12, pp.198-202, (2015)

[14] M. Levina and A. A. Hasinoff, "The silicon valley ethos: tech industry products, discourses, and practices," Telev. New Media, vol.18, no.6, pp.489-495, (2017) DOI: 10.1177/1527476416680454

[15] Syamsudin R.N., Sukardi S., and Shiyu H., "Vocational high school teachers' efforts in equipping graduates with soft skills based on work demands," Jurnal Pendidikan Teknologi dan Kejuruan, vol.24, no.2, pp.303309, (2018) 
A Review on The Importance of Teacher's Efforts to Prepare High-School Graduates' Soft Skills in Vocational High School

This page is empty by intention. 